\title{
Fatty acid amide hydrolase inhibitor relieves neuropathic pain-induced depressive-like behaviors independent its anti-nociceptive effects in rats: involvement of hippocampal neurogenesis
}

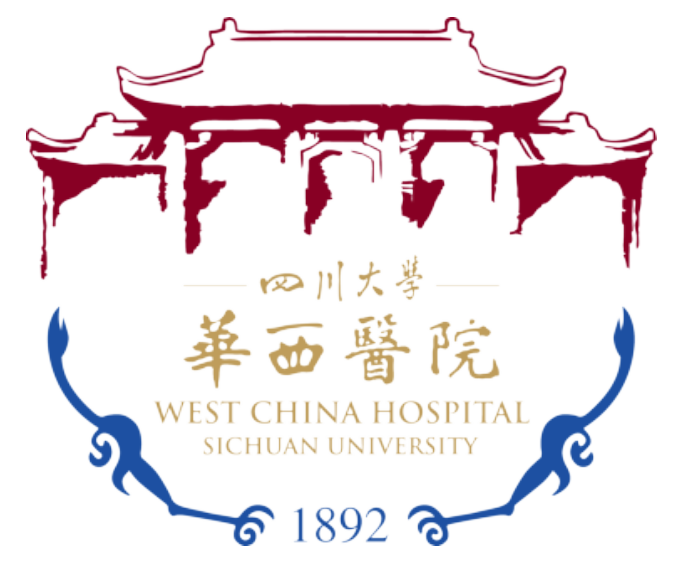

\author{
Haixia Jiang, Chen Zhou, Jin Liu \\ Department of Anesthesiology, West China Hospital of Sichuan University, Chengdu, \\ China
}

\begin{abstract}
Background
Neuropathic pain is often associated with depression. Hippocampal neurogenesis has been implicated in animal models of depression induced by neuropathic pain and behavioral effects of antidepressant. Fatty acid amide hydrolase (FAAH) inhibitors of endocannabinoid (eCB) system could treat neuropathic pain and relieve depression-like behaviors in chronic mild stress model of rats. However, it is unclear whether FAAH inhibitor can relieve neuropathic pain-induced depression by and not by its antinociceptive effects, and the underling cellular mechanisms remain unknown.
\end{abstract}

\section{Methods}

Chronic constriction injury (CCI) of sciatic nerve was chosen as a model of neuropathic pain in rats. Rats were repeatedly administered systemically FAAH inhibitor URB597 $(4.8 \mathrm{mg} / \mathrm{kg})$ or peripherally restricted FAAH inhibitor URB937 $(1.6 \mathrm{mg} / \mathrm{kg}$, intraperitoneal, once daily) from the day 15 to 28 after CCI. Mechanical withdrawal threshold was examined by Von Frey test before surgery and on days 7,14,21 and 28 after CCI. Depressivelike behaviors were evaluated by forced swim test (FST) and novelty suppressed feeding (NSF) on day 29 after CCI. The levels of AEA and 2-AG in the hippocampus were examined by Liquid Chromatography and Mass Spectrometry. mRNA levels of $\mathrm{CB}_{1}$ receptor, $\mathrm{CB}_{2}$ receptor and Brain derived nerve factor (BDNF) in the hippocampus were determined using Quantitative polymerase chain reaction (qPCR). Hippocampal neurogenesis including proliferation, differentiation and survival of newborn cells were assessed by immunohistochemistry.

\section{Results}

After CCI injury, the rats developed nociceptive and depressive-like behaviors, as shown by mechanical hypersensitivity in Von Frey test $(\mathrm{P}<0.001)$, and significantly prolonged time of immobility in FST (sham : $83.7 \pm 14.1 \mathrm{~s}, \quad \mathrm{CCI}: 137.9 \pm 18.8 \mathrm{~s}, \quad \mathrm{P}<0.001$ ) and protracted latency to feed in NSF (sham:133.4 $\pm 19.4 \mathrm{~s}, \mathrm{CCI}: 234.9 \pm 33.5 \mathrm{~s}$, $\mathrm{P}<0.001)$. In CCI rats sub-chronic URB597 or URB937 administration significantly increased the mechanical withdrawal threshold (CCI+vehicle : $3.1 \pm 1.0 \mathrm{~g}, \quad \mathrm{CCI}+\mathrm{URB} 597: 11.2 \pm 1.2 \mathrm{~g}$, $\mathrm{P}<0.001 ;$ CCI+URB937 : $12.1 \pm 1.3 \mathrm{~g}, \quad \mathrm{P}<0.001)$. While only subchronic URB597 treatment significantly relieved the depressive-like behaviors in CCI rats (FST : CCI+vehicle : $135.8 \pm 16.6 \mathrm{~s}$, CCI +URB597 : 85.3 $\pm 17.2 \mathrm{~s}, \quad \mathrm{P}<0.001 ; \mathrm{CCI}+\mathrm{URB} 937: 129.6 \pm 17.8 \mathrm{~s}$,

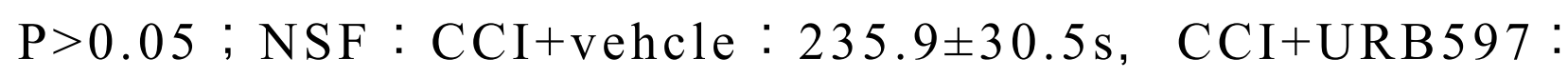
$131.8 \pm 19.8 \mathrm{~s}, \quad \mathrm{P}<0.001 ; \mathrm{CCI}+\mathrm{URB} 937: 232.2 \pm 33.2 \mathrm{~s}, \quad \mathrm{P}>0.05$, Fig. 1). Single URB597 or URB937 administration attenuated the nociceptive behaviors with little effect on the depressive-like behaviors in CCI rats. Meanwhile CCI decreased the $\mathrm{CB}_{1}$ receptor and BDNF mRNA levels in the hippocampus, and impaired hippocampal neurogenesis, as shown by the decreased number of proliferated cells and the survived new neurons, while sub-chronic URB597 treatments increased the hippocampal AEA levels and reversed these deficits on $\mathrm{CB}_{1}$ receptor and adult neurogenesis (Fig.2). Sub-chronic URB937 treatment had no effect on AEA level, mRNA levels of $\mathrm{CB}_{1}$ receptor and adult neurogenesis in the hippocampus.

Figure 1

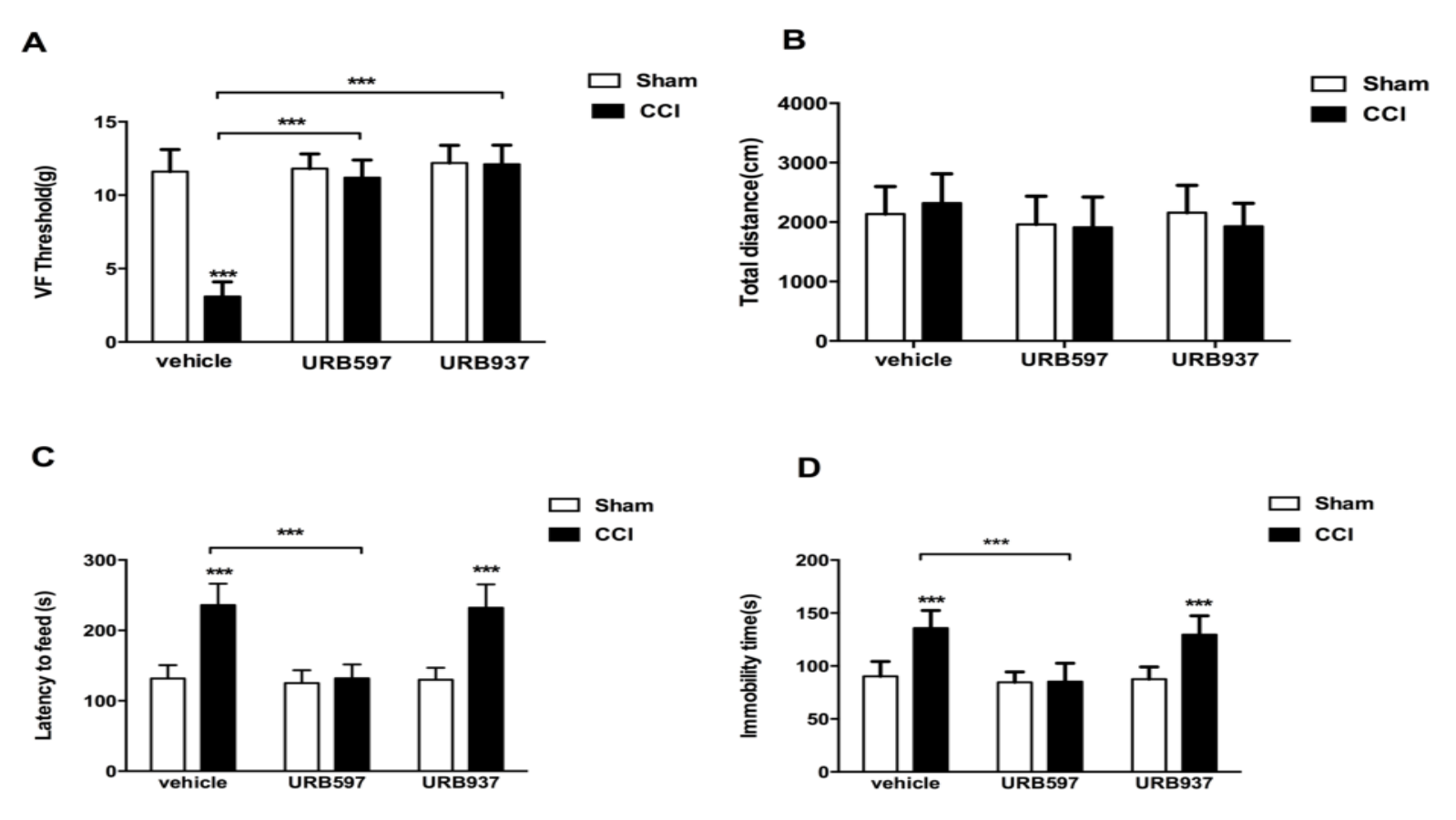

Figure 2

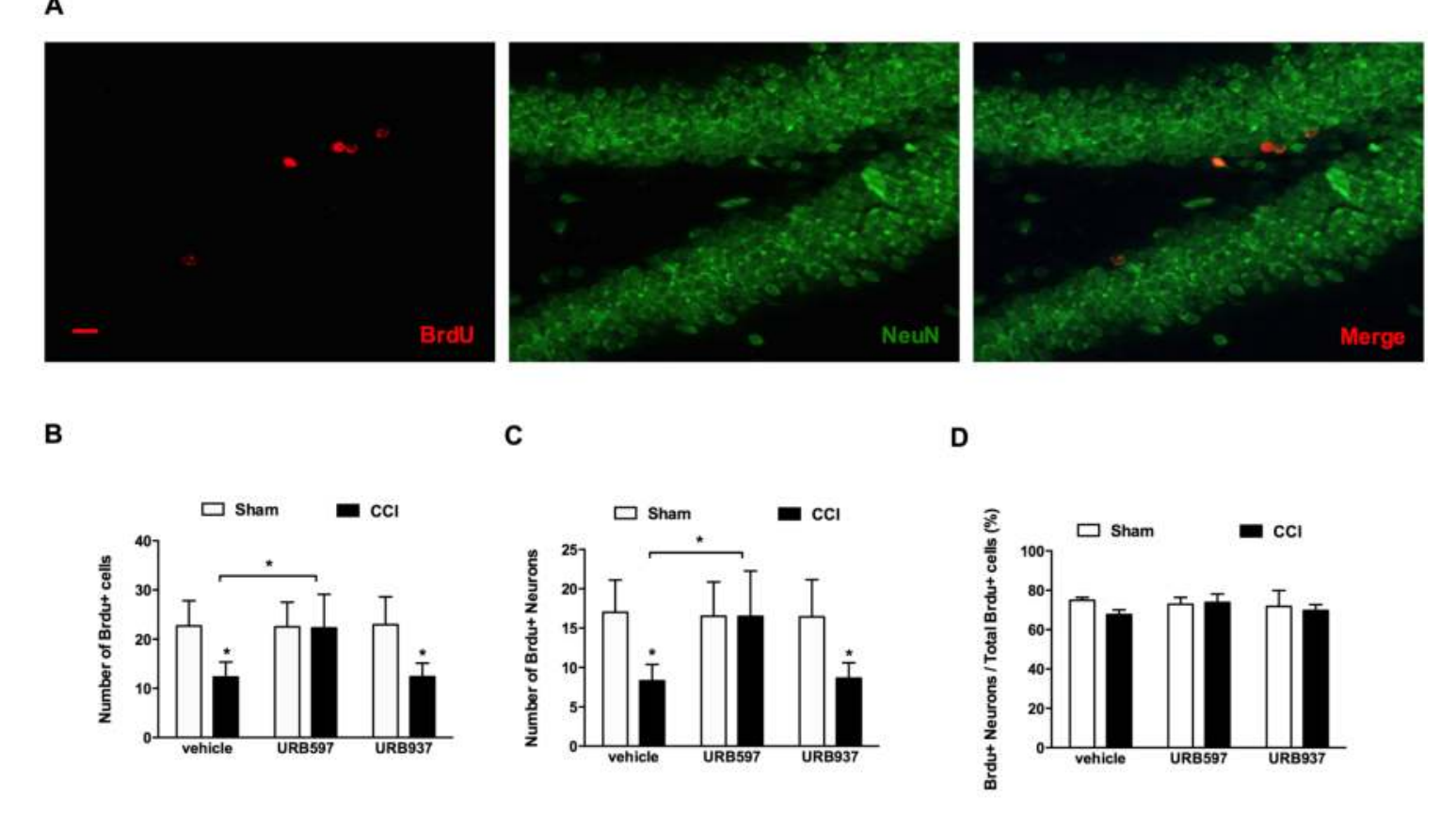

conclusion

Systemically FAAH inhibitor could treat neuropathic pain-induced depressive-like behaviors independent of its peripheral analgesic actions. This anti-depressive effect may result from improving the impaired hippocampal adult neurogenesis by enhancing eCB signal. 